Abstracta Iranica Iranica

Revue bibliographique pour le domaine irano-aryen

Volume 32-33 | 2013

Comptes rendus des publications de 2009-2010

\title{
Hadi Maktabi. Under the peacock throne: carpets, felts, and silks in Persian painting, 1736-1834
}

\section{Nourane Ben Azzouna}

\section{(2) OpenEdition}

12 Journals

Édition électronique

URL : http://journals.openedition.org/abstractairanica/40799

DOI : 10.4000/abstractairanica.40799

ISSN : 1961-960X

\section{Éditeur :}

CNRS (UMR 7528 Mondes iraniens et indiens), Éditions de l'IFRI

\section{Édition imprimée}

Date de publication : 1 décembre 2013

ISSN : 0240-8910

\section{Référence électronique}

Nourane Ben Azzouna, « Hadi Maktabi. Under the peacock throne: carpets, felts, and silks in Persian painting, 1736-1834 », Abstracta Iranica [En ligne], Volume 32-33 | 2013, document 306, mis en ligne le 01 juillet 2016, consulté le 26 septembre 2020. URL : http://journals.openedition.org/abstractairanica/ 40799 ; DOI : https://doi.org/10.4000/abstractairanica.40799

Ce document a été généré automatiquement le 26 septembre 2020.

Tous droits réservés 


\title{
Hadi Maktabi. Under the peacock throne: carpets, felts, and silks in Persian painting, 1736-1834
}

\author{
Nourane Ben Azzouna
}

\section{RÉFÉRENCE}

Hadi Maktabi. « Under the peacock throne: carpets, felts, and silks in Persian painting, 1736-1834 ». Muqarnas, 26, 2009, p. 317-347.

1 Cet article est une nouvelle étude qui, textes et objets à l'appui, montre que la peinture persane est une source visuelle fiable sur la culture matérielle contemporaine, en l'occurrence ici les tapis et autres textiles de sol en feutre et en soie à l'époque des dynasties Afs̄ār (1736-1796) et Zand (1760-1793), et au début des Qājārs (1785-1834). Les textes utilisés sont des ouvrages historiques persans et des récits de voyageurs occidentaux. Ils sont confrontés aux tapis conservés, ainsi qu'aux peintures contemporaines sur divers supports: toile, papier, laque. L'étude suit un plan chronologique. Elle révèle la continuité de certaines traditions, comme celle de superposer plusieurs tapis en contexte royal, mais également certaines modes plus circonstancielles. Par exemple, des portraits de Nāder Šāh (1736-1747) visiblement postérieurs à son invasion de l'Inde en 1739 montrent des textiles et autres objets moghols. D'autres peintures donnent des indications sur l'usage cérémonial de certains tapis comme les grands tapis à décor de treillis de Kermān, ou l'usage plus privé d'autres types de tapis comme les min̄ā-Hānī. 


\section{AUTEURS}

\section{NOURANE BEN AZZOUNA}

Agence France Muséums-Louvre, Abu Dhabi 